V.S. Malyar, A.V. Malyar

\title{
MECHANICAL CHARACTERISTICS OF THREE-PHASE INDUCTION MOTORS WITH SINGLE-PHASE POWER SUPPLY
}

\begin{abstract}
Aim. Development of a method for calculating mechanical characteristics of three-phase induction motors with single-phase power supply. Methods. The developed algorithm is based on the high-adequacy mathematical model of motor and projection method for solving the boundary problem for equations of electrical circuits balance presented in the three-phase coordinate system. As a result of asymmetry of power supply to the stator windings, in steady state, flux-linkage and current change according to the periodic law. They are determined by solving the boundary problem. Results. The developed mathematical model allows determining periodic dependence of coordinates as a function of slip and, based on them, mechanical characteristics of motors. Academic novelty. The developed method relies on a completely new mathematical approach to calculation of stationary modes of nonlinear electromagnetic circuits, which allows obtaining periodic solution in a timeless domain. Practical value. Using the developed calculation algorithm, one can select capacitance required to start an induction motor with single-phase power supply and calculate static mechanical characteristics at a given capacitance. References 5, figures 3 .
\end{abstract}

Key words: mechanical characteristic, induction motor, single-phase power supply, boundary problem, projection method, capacitor.

Предложен метод расчета механических характеристик трехфазных асинхронных двигателей, которые питаются от однофазной сети. Врацающееся магнитное поле создается за счет включения последовательно в одну фазу конденсаторов. Задача решается как краевая в трехфазной системе координат. В математической модели двигателя учитывается насыщение магнитопровода и вытеснение тока. Библ. 5 , рис. 3.

Ключевые слова: механическая характеристика, асинхронный двигатель, однофазное питание, краевая задача, проекционный метод, конденсатор.

Introduction. Induction motors (IM) are mainly produced with three-phase windings that are powered symmetrical three-phase system voltages. However, in practice may need to switch to a single-phase network [1], which use capacitors that create shifting the phase current in a coil and a magnetic field motor becomes pulsating and rotating, causing electromagnetic torque. Also developed and are widely used capacitor electric motors, which are designed to operate on single-phase network [5]. And in the first and second cases, there is a problem of calculation of their starting characteristics and capacitors' capacitance choice.

In technical literature since the calculation method for different values of capacitors are known [1,2], but these methods are not sufficient accuracy, since not adequately take into account factors such as asymmetry of power magnetic saturation and displacement current. Problems of analysis of operation modes of IM by mathematical modeling needs to solve two problems: the choice of a mathematical model of the motor and the method of calculation. These problems are interrelated, since using a simplified mathematical model of IM can not adequately take into account the factors that determine the accuracy of the calculations, and the use of more complex models requires utilization of appropriate mathematical apparatus.

The goal of the work is developing methods and algorithm of calculation of mechanical characteristics of asynchronous motors that are powered by a singlephase network.

The system of equations. A three-phase IM with capacitors in one phase by definition is skewed on the part of the stator, and therefore for the analysis of electromagnetic processes in their most adequate and optimal coordinate system is a three-phase, but not physical, so-called inhibited [4]. In this system the outlines of the stator are not converted, allowing adequately describe processes in them, and three-phase winding rotor is replaced by an equivalent stationary phase, the axis of which coincides with the axis of the stator winding.

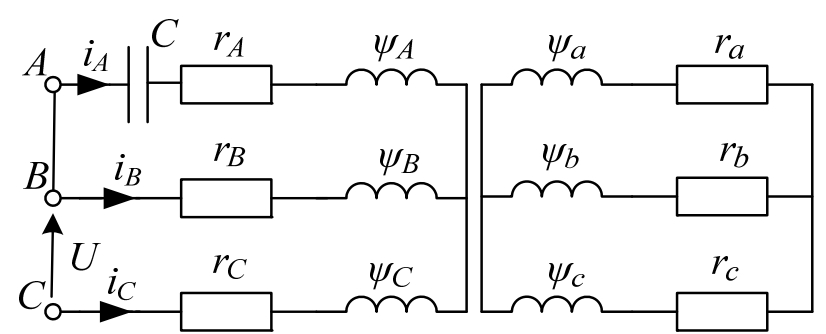

Fig. 1

The system of equations describing the electromagnetic processes in IM, three-phase stator winding is powered from a single-phase network shown in Fig. 1 has the form [4]

$$
\begin{aligned}
& \frac{d \psi_{A}}{d t}-\frac{d \psi_{B}}{d t}=-r_{A} i_{A}+r_{B} i_{B}-u_{k} ; \\
& \frac{d \psi_{B}}{d t}-\frac{d \psi_{C}}{d t}=-r_{B} i_{B}+r_{C} i_{C}+u_{B C} ; \\
& i_{A}+i_{B}+i_{C}=0 ; \\
& \frac{d \psi_{a}}{d t}-\frac{d \psi_{b}}{d t}=-r_{a} i_{a}+r_{b} i_{b}-\alpha\left(\psi_{b}-2 \psi_{c}+\psi_{a}\right) ; \\
& \frac{d \psi_{b}}{d t}-\frac{d \psi_{c}}{d t}=-r_{b} i_{b}+r_{c} i_{c}-\alpha\left(\psi_{c}-2 \psi_{a}+\psi_{b}\right) ; \\
& i_{a}+i_{b}+i_{c}=0 ; \\
& \frac{d u_{k}}{d t}=\frac{i_{A}}{C},
\end{aligned}
$$

(C) V.S. Malyar, A.V. Malyar 
where $u_{B C}=\sqrt{3} U_{m} \sin \left(\omega_{0} t-\pi / 2\right)$ is the linear supply voltage; $U_{m}, \omega_{0}$ are the phase voltage amplitude and angular frequency; $\alpha=\omega_{0}(1-s) / \sqrt{3} ; s$ is the slip; $\psi_{\xi}, i_{\xi}, r_{\xi}$ ( $\xi=A, B, C, a, b, c)$ are the flux linkages, currents and active supports of circuits; $u_{k}$ is the voltage on the capacitor with capacitance $C$.

A technique and algorithm of calculation. We write (1) by one vector equation $m=7$ th order in the form

$$
A \frac{d \vec{y}}{d t}=B \vec{y}+D \vec{x}+\vec{u}
$$

where
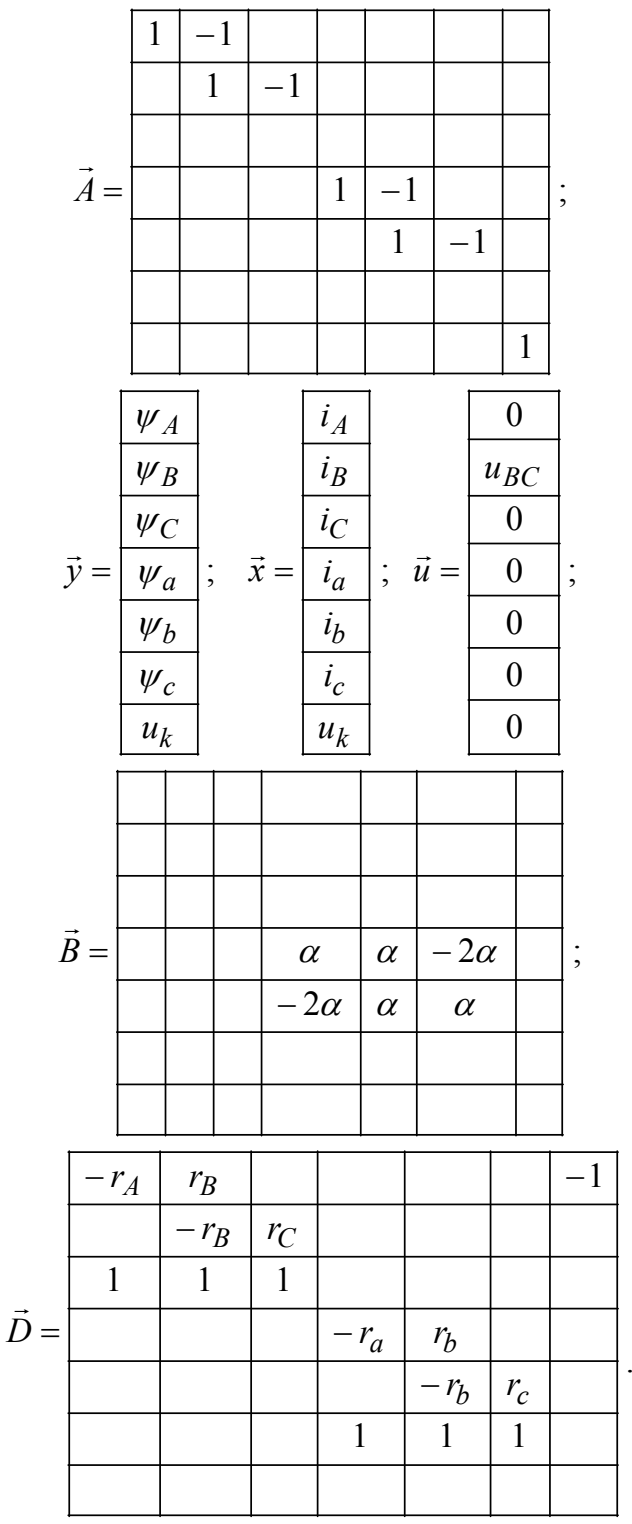

The system of differential equations (2) in the form of Cauchy looks

$$
\frac{d \vec{y}(\vec{x}, t)}{d t}=z(\vec{y}, \vec{x}, \vec{u}, t) .
$$

Since the vector $\vec{u}(t)=\vec{u}(t+T)$ is a periodic function of time, in the steady state (at $s=$ const) the solution of the system of equation (3) is $T$-periodic dependences of the vector $\vec{x}(t)=\vec{x}(t+T)$ components. Determining the periodic functional relationships of the vector $\vec{x}$ components by calculating the transition to institutionalization unacceptable for many reasons. Such a problem can most effectively be solved in a timeless region by solving the boundary problem developed on the basis of the general theory of nonlinear oscillations projection method based on a theoretical approximation coordinates state splines of third order [3]. Formation of the boundary problem is carried out on a grid of $n$ nodal points of the period $T$. The result of approximating one differential equation of the system (3) is a system of algebraic equations of the $n$-th order

$$
H \vec{Y}-\vec{Z}=\vec{U},
$$

where $H$ is the transition matrix from continuous coordinates to their nodal values, elements of which are determined by only mesh nodes [3]; $\vec{Y}=\left(\overline{y_{1}, y_{n}}\right)^{*} ; \vec{Z}=\left(\overline{z_{1}, z_{n}}\right)^{*} ; \vec{U}=\left(\overline{u_{1}, u_{n}}\right)^{*}$, and for the system of differential equations $(2)-m$ vector equations in the form (4)

$$
H_{c} \vec{Y}_{c}-\vec{Z}_{c}=\vec{U}_{c}
$$

where $H_{c}=\operatorname{diag}\left(\overline{H_{1}, H_{m}}\right) ; \vec{Y}_{c}=\left(\overline{\vec{Y}_{1}, \vec{Y}_{m}}\right)^{*}$; $\vec{Z}_{c}=\left({\overrightarrow{Z_{1}, \vec{Z}_{m}}}^{*} ; \vec{U}_{c}=\left(\overline{\vec{U}_{1}, \vec{U}_{m}}\right)^{*}\right.$

Nonlinear system (5) of algebraic equations of $m n$-th order is a discrete reflection of nonlinear system of differential equations (2) order $m$ and it approximates to the period $T$. Its solution is a vector $\vec{X}$ whose components are the values of currents legs and voltage on the capacitor in the grid. With its help you can calculate not only steady but also investigate the impact of the operation of the motor change any position, which is part of the system. To calculate the steady mode for a given slide the method of continuation on parameter. For this system (5) we enter the parameter $\varepsilon$ by multiplying the voltage vector applied to $\varepsilon$ and differentiate her on it. As a result, we obtain the differential equation (DE)

$$
W \frac{d \vec{X}_{c}}{d \varepsilon}=\vec{U}_{c}
$$

where $W=\left(H_{c}-\frac{\partial \vec{Z}_{c}}{\partial \vec{Y}_{c}}\right) \frac{\partial \vec{Y}_{c}}{\partial \vec{X}_{c}}-\frac{\partial \vec{Z}_{c}}{\partial \vec{X}_{c}}$ is the Jacobi matrix block elements of which $\left.\frac{\partial \vec{y}}{\partial \vec{x}}\right|_{j},\left.\frac{\partial \vec{z}}{\partial \vec{y}}\right|_{j},\left.\frac{\partial \vec{z}}{\partial \vec{x}}\right|_{j}$ are determined by values of IM parameters in the $j$-th node.

$$
\left.\frac{\partial \vec{y}}{\partial \vec{x}}\right|_{j}=\begin{array}{|c|c|}
\hline L_{j} & 0 \\
\hline 0 & 1
\end{array} ;\left.\frac{\partial \vec{z}}{\partial \vec{y}}\right|_{j}=B ;\left.\frac{\partial \vec{z}}{\partial \vec{x}}\right|_{j}=D
$$




$L_{j}=$\begin{tabular}{|l|l|l|l|l|l|}
\hline$L_{A A j}$ & $L_{A B j}$ & $L_{A C j}$ & $L_{A a j}$ & $L_{A b j}$ & $L_{A c j}$ \\
\hline$L_{B A j}$ & $L_{B B j}$ & $L_{B C j}$ & $L_{B a j}$ & $L_{B b j}$ & $L_{B c j}$ \\
\hline$L_{C A j}$ & $L_{C B j}$ & $L_{C C j}$ & $L_{C a j}$ & $L_{C b j}$ & $L_{C c j}$ \\
\hline$L_{a A j}$ & $L_{a B j}$ & $L_{a C j}$ & $L_{a a j}$ & $L_{a b j}$ & $L_{a c j}$ \\
\hline$L_{b A j}$ & $L_{b B j}$ & $L_{b C j}$ & $L_{b a j}$ & $L_{b b j}$ & $L_{b c j}$ \\
\hline$L_{c A j}$ & $L_{c B j}$ & $L_{c C j}$ & $L_{c a j}$ & $L_{c b j}$ & $L_{c c j}$ \\
\hline
\end{tabular}

Integrating system of DR (6) by $\varepsilon$ from $\varepsilon=0$ to $\varepsilon=1$ we find the values of the vector $\vec{X}$ at a given voltage, which can be refined by Newton method.

To investigate the effect on IM operation mode of the change any coordinates needed considering the vector applied voltage unchanged we differentiate the system (5) by this coordinate as a parameter. In particular when calculating the mechanical characteristics we obtain the system of DE

$$
W \frac{d \vec{X}_{c}}{d s}=\frac{\partial \vec{Z}_{c}}{\partial s},
$$

integrating which we obtain a multi-dimensional characteristic. Thus Jacobi matrix such as in (6) and a right parts vector consists of $n$ vectors in the form

$$
\left.\frac{\partial \vec{z}}{\partial s}\right|_{j}=\frac{\partial B}{\partial s} \vec{y}_{j},
$$

where $\partial B / \partial s$ equals to the matrix $B$ in which $\alpha=-\omega_{0} / \sqrt{3}$.

The problem of calculating the mechanical characteristics is solved in two stages: at the first we calculate the steady mode at slip $s=1.0$, and at the second - dependences of coordinates as a function of the slip from $s=$ 1.0 to the specified value, and based on it - mechanical characteristic $M_{e}=M_{e}(s)$. The electromagnetic moment of IM is calculated by the formula [4]

$$
M_{e}=\frac{p}{\sqrt{3}} I_{\mu}\left(\left(i_{\mu B}-i_{\mu C}\right) i_{A}+\left(i_{\mu C}-i_{\mu A}\right) i_{B}+\left(i_{\mu A}-i_{\mu B}\right) i_{C}\right) \text {. }
$$

To determine the matrix elements $L_{j}$ of differentiated inductances characteristic magnetization of the main magnetic path and scattering depending flux leakages of the stator $(s)$ and rotor $(r)$ of the respective current are used [4]

$$
\psi_{\mu}=\psi_{\mu}\left(i_{\mu}\right), \psi_{\sigma s}=\psi_{\sigma s}\left(i_{s}\right), \psi_{\sigma r}=\psi_{\sigma r}\left(i_{r}\right),
$$

where $i_{s}, i_{r}$ are the modules of vectors representing these currents.

To take into account of the displacement current in rotor bars each of them together with short-circuited rings divided by height into $k$ layers. That is believed that the rotor there are $k$ short-circuited windings with the appropriate dimensions and each are substituted by three-phase one. Under these conditions, the system of equations (1) instead of three equations for the rotor we must write $3 k$ equations like

$$
\begin{aligned}
& \frac{d \psi_{a k}}{d t}-\frac{d \psi_{b k}}{d t}= \\
& =-r_{a k} i_{a k}+r_{b k} i_{b k}-\alpha\left(\psi_{b k}-2 \psi_{c k}+\psi_{a k}\right) ; \\
& \frac{d \psi_{b k}}{d t}-\frac{d \psi_{c k}}{d t}= \\
& =-r_{b k} i_{b k}+r_{c k} i_{c k}-\alpha\left(\psi_{c k}-2 \psi_{a k}+\psi_{b k}\right) ; \\
& i_{a k}+i_{b k}+i_{c k}=0 .
\end{aligned}
$$

Increasing the number of equations does not change the calculation algorithm and has little effect on the amount of computation as poorly filled Jacobi matrix, allowing for solving the system of equations using an algorithm that takes into account its structure.

Examples of results of mathematical modeling are shown in Fig. 2, 3.

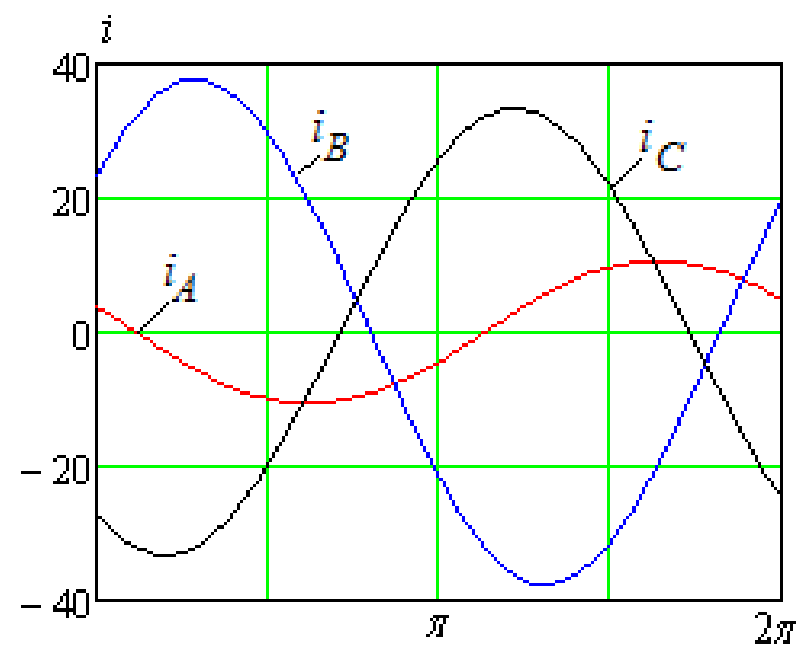

Fig. 2. Periodical dependences of phase currents of the motor 4A80B2Y3 at slip $s=1.0$ and capacitors' capacitance $C=100 \mu \mathrm{F}$

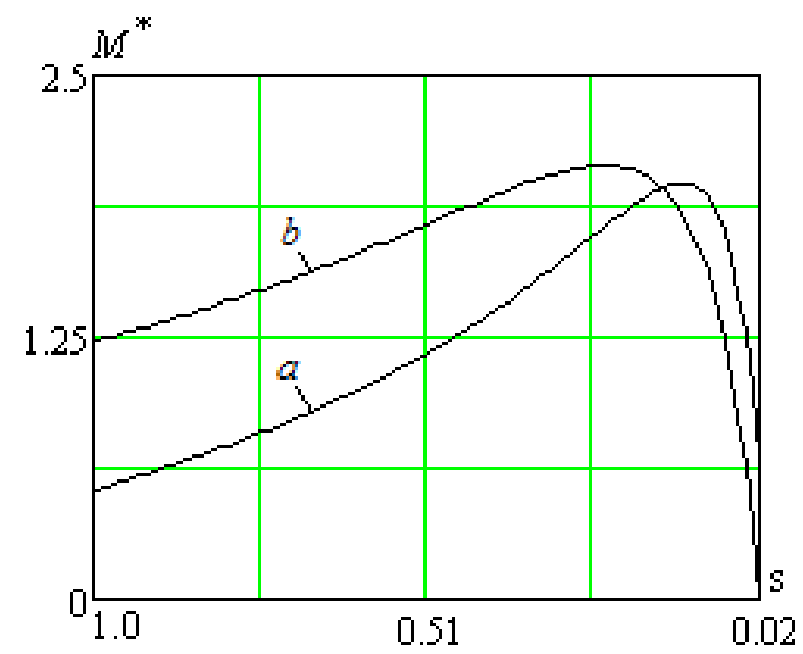

Fig. 3. Static mechanical characteristics of the motor 4A80B2Y3 at various capacitors' capacitances: $C=100 \mu \mathrm{F}(a)$ and $C=200 \mu \mathrm{F}(b)$ 


\section{Conclusion.}

The developed method of calculation of static mechanical properties of three-phase squirrel cage IM that are powered by a single-phase network allows you to explore the influence of capacitors' capacitance on the process to select a start and its value, which provides the necessary starting torque. The basis of the algorithm is a mathematical model of IM, which considers magnetic saturation and displacement of current in the bars of the rotor, and the differential method for calculating the static characteristics based on solving the boundary problem for a system of differential equations of electrical balance.

\section{REFERENCES}

1. Bespalov V.Ya., Moshchynskyy Yu.A., Petrov A.P. Dynamic indicators of three-phase induction motors connected to single-phase supply. Elektrotekhnika - Electrical engineering, 2000, no.1, pp. 13-19. (Rus).

2. Beshta A.S., Semin A.A. Evaluation of parameters of the equivalent circuit of the induction motor for asymmetrical power supply to the stator. Elektromekhanichni $i$ enerhozberihaiuchi systemy - Electromechanical and energy saving systems, 2014, vol. 2, pp. 10-16. (Rus).

How to cite this article:

Malyar V.S., Malyar A.V. Mechanical characteristics of three-phase induction motors with single-phase power supply. Electrical engineering \& electromechanics, 2016, no.3, pp. 21-24. doi: 10.20998/2074-272X.2016.3.03.
3. Malyar V.S., Malyar A.V. Mathematical modeling of periodic modes of electrotechnical devices. Electronnoe modelirovanie - Electronic Modeling, 2005, vol.27, no.3, pp. 39-53. (Rus).

4. Fyl'ts R.V. Matematicheskie osnovy teorii elektromekhanicheskikh preobrazovatelei [Mathematical foundations of the theory of electromechanical transducers]. Kyiv, Naukova Dumka Publ., 1979. 208 p. (Rus).

5. Shurub Yu.V. A mathematical model of an asynchronous capasitor engine with a thyristor control. Tekhnichna elektrodynamika - Technical electrodynamics, 1999, no.4, pp. 52-56. (Rus).

Received 09.03.2016

V.S. Malyar ${ }^{1}$, Doctor of Technical Science, Professor, A.V. Malyar ${ }^{1}$, Doctor of Technical Science, Professor, ${ }^{1}$ Lviv Polytechnic National University,

12, S. Bandera Str., Lviv, 79013, Ukraine, phone +380322582119 ,

e-mail: svmalyar@polynet.lviv.ua 